\title{
Incorporating theology into medical education
}

I t's a simple proposition: All Canadian physicians should receive mandatory training in the provision of "spiritual health care."

There are those, such as Dr. Harold G. Koenig, professor of psychiatry and behavioral sciences and associate professor of medicine at the Duke University Medical Center in North Carolina, who hold unequivocal positions on the issue.

"All medical schools in Canada should include a dedicated, required course on spirituality and medicine to expose students to the research on religion, spirituality and health, and how this affects medical outcomes; the rationale behind integrating spirituality into patient care; how to take a spiritual history and address spiritual needs; when to refer patients to chaplains and the limitations and boundaries involved in physicians addressing spiritual issues," Koenig writes in an email.

"Currently, the only physicians who are assessing and addressing spiritual issues in clinical practice are devoutly religious physicians," he adds. "Thus, addressing spiritual issues is physiciancentered. This is the opposite of the way it should be. Health care should be patient-centered, not doctor-centered. Thus, the reason why spiritual issues should be assessed and addressed is because of their importance to patients, effects on medical decisions, and impact on health outcomes."

There are those in Canada, which at least nominally has a more secular history than the United States, who might find such a notion anathema.

But the concept does appear to be making some in-roads north of the 49th parallel. While none of Canada's 17 medical schools has yet made a course in spiritual health care a prerequisite toward obtaining an $\mathrm{MD}$, several are incorporating some facets of spiritual health care into courses. And with the province of Manitoba having recently unveiled a spiritual health care strategic plan (www.cmaj.ca/lookup

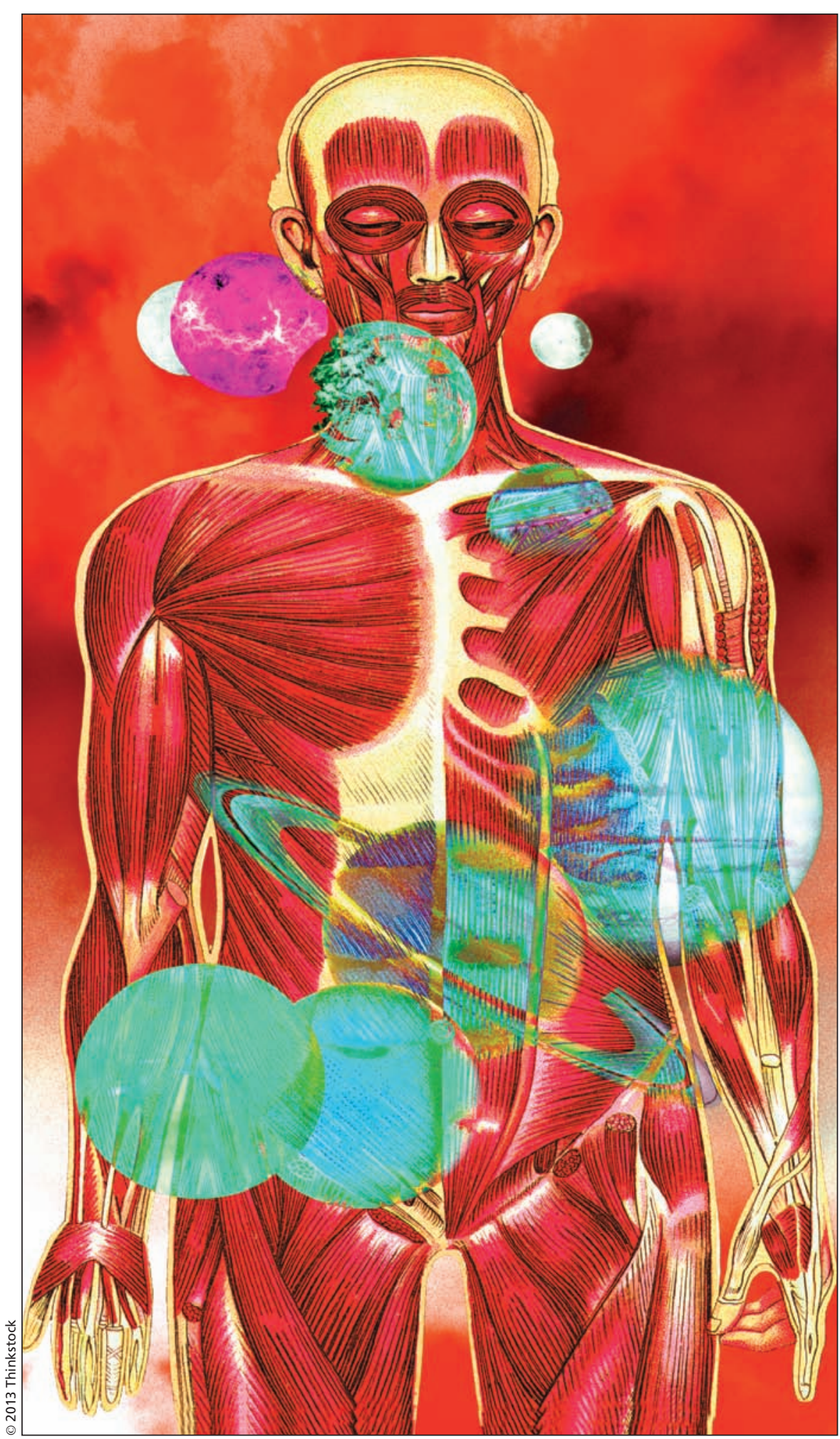

Dedicated courses on spirituality and medicine, not just anatomy, should be stock-andtrade at medical schools, some educators argue. 
/doi/10.1503/cmaj.109-4314), the pressure to expand such programming will likely increase.

But the notion of compelling spiritual health care pedagogy seems to have fallen off the table since the mid-2000s, when former Association of Faculties of Medicine of Canada (AFMC) executive director Dr. David Hawkins was heavily involved in the Canadian Medical Education Initiative, which aimed to incorporate more teaching of spirituality in medical schools.

What has emerged instead are piecemeal approaches based on individual medical school preferences. "I think it's on the agenda of all [Canadian medical schools] indirectly," says Dr. Nick Busing, president and CEO of the AFMC.

But it's typically discussed in very broad terms or in the context of specific subpopulations, such as First Nations people, for whom spiritual beliefs and religious rituals often have substantial significance, Busing adds. "In those kinds of ways there is some leakage to issues of spirituality. There are courses on humanism and in those courses on humanism and medicine, the spiritual context is part of the discussion."

"I think what our medical students need to learn about and understand is that our patients who we see, all of these patients come with a spiritual dimension to their lives," Busing says. "Physicians have to: number one, recognize there is a spiritual dimension; number two, know what resources to turn to if they need some help in addressing those; and number three, where relevant and appropriate, acknowledge it with the patient."

There's been considerable, if informal, progress on the spiritual pedagogy front with Canadian medical schools over the past decade, says Dr. Lisa Graves, associate dean of undergraduate medical education at the Northern Ontario School of Medicine in Sudbury, Ontario, and cochair of the AFMC standing committee on undergraduate medical education. "The move to increase rigour and focus around the teaching of communications skills, context-based care, patientcentered medicine, understanding health care in its complete context and understanding the role that spirituality will play I think has given spirituality a place that it may not have had explicitly in medical school curriculums in the past."

But there are constant pressures on curricula, she adds. "The real challenge in Canadian medical education [is] that pretty much every issue, disease or concept on the planet could benefit from the same sort of endeavor, so the question becomes how many of these types of requests can one address?" she says. "With limited resources and limited time which ones do we focus on? ... We can't fit everything in the curriculum."'

By contrast, spiritual health care appears on a sharper curve of incorporation into medical school curricula in the US. According to the Association of American Medical Colleges medical education database CurrMitt, which captures about $50 \%$ of medical school data in the US, 61 schools reported having covered spirituality in 268 teaching sessions presented in 151 required and selective courses in 2011. Three schools have a course specifically on the topic of religion and/or spirituality. Meanwhile, a 2010 Duke survey of 115 medical school deans indicated that $90 \%$ had courses or content on spirituality and health, and in $7 \%$ of cases, such courses were required.

Others suggest the degree to which spiritual health care has permeated American medical education is even greater than the numbers suggest.

"It comes in courses that are labelled things like clinical skills, doctor-patient relationships, social and behavioural factors, in psychiatry clerkships, sometimes in the internal medicine clerkships," says Carol Aschenbrener, chief medical education officer for the Association of American Medical Colleges. "Anecdotally, probably more than that are going to get exposure to it if they have a course or an elective around palliative care or if they spend time in a geriatrics unit, so it's contextually dependent and I would say that our best estimate is that at least $50 \%$ of US medical schools have some coverage of spirituality in medicine."

The greater extent to which spiritual health care has infiltrated American medical education is a function of the
Association of American Medical Colleges having been more collaborative about such reform than was the AFMC, says Dr. Christina Puchalski, director of the George Washington Institute for Spirituality \& Health and professor of medicine and health sciences at the George Washington University School of Medicine in Washington, DC.

Canada might have moved along the same trajectory if a survey of Canadian medical deans had not elicited a lukewarm response, adds Puchalski, coauthor of a book, Making Health Care Whole: Integrating Spirituality into Patient Care (West Conshohocken, Pennsylvania: Templeton Press; 2010), which the Manitoba government says was the primary basis for its spiritual health care strategic plan.

"I think that some deans see it as religion only and are suspicious," Puchalski says. "Of course, spirituality is so much broader and in spite of our materials that state that, there is some resistance - we had that in this country too."

It's important to separate religion from spirituality and to understand the extent to which attending to a patient's spiritual needs is an "integral" element of providing good health care, says Aschenbrener. It's "part of caring for the whole person, it's not something separate that's sitting off to the side some place and therefore in a separate course. Rather, it's something that needs to be integrated with care for the whole patient."

"You want it to be a part of the physician's approach to the patient, not something separate that they think about once and a while," she adds.

Canadian physicians who are enthused about providing spiritual health care, such as Dr. Doreen Oneschuk, palliative medicine physician at the Edmonton Regional Palliative Medicine Program in Alberta, expect progress toward curricula reform to be incremental.

"I think what we're doing is trying to bring this to [medical students'] attention, to show that this is an important part of patient assessment," says Oneschuk, who along with colleagues was able to convince University of Alberta administrators to include a session on spiritual health care last year. "It was very well received, the students 
seemed to really want to discuss this topic and I know it's just a tiny portion in the curriculum but we were able to introduce it," she says. "It would be wonderful to see something like this happen even on a smaller scale so that all universities do incorporate this and not just at the medical schools but at an inter-professional level, which is where medical education is heading and where more emphasis is being placed on working in teams." - Adam Miller, CMAJ

CMAJ 2013. DOI:10.1503/cmaj.109-4317
Editor's note: Second of a two-part series.

Part I: Zen meets medicine

(www.cmaj.ca/lookup/doi/10.1503 /cmaj.109-4314). 